Magnus Ronn | LM Tucker | Ron Dulaney Jr. Sinclair, Mousazadeh, Safarzadeh | James Shraiky Marci Uihlein | Tang, Anderson, Aksamija, Hodge

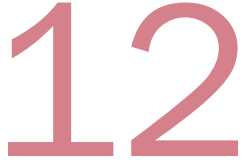

volume 9 | issue 1

\section{Architecture, Structure, and Loads: A Moment of Change?}

\author{
Marci S. Uihlein, School of Architecture \\ University of Illinois at Urbana-Champaign
}

\section{Introduction}

Architecture and building structure have a unique, complicated, and intertwined history. Architectural innovations can drive the development of structural systems and structural advancements can push architecture forward. Rem Koolhaas, writing about one of his primary engineering collaborators in 2002, stated that this collaborator "almost single『 handedly shifted the ground in engineering - a domain which the earth moves very rarely - and therefore enabled architecture to be imagined differently."1 There are two ideas embedded in this quote. The first is that building structure and those who design it are entrenched in a way of practice that seldom varies. The second is that the view of structure is changing and this change has the potential to allow architecture to make a significant transformation. Ten years later, the question remains, is structure changing, and if so, how and what metrics can be used to establish this?

Digital technology and fabrication advancements have led to an exploration of building structure and material. Architects are creating buildings once thought impossible to build. Through experimentation, new forms and roof systems are being created. Does this form creation have a larger meaning? One indicator of this might be found in the way loads and load paths are conceived. When starting a project, the primary determinants are the understanding of the loads created by the engineer and the selection of a structural system to support them. Can an examination of loads be used to evaluate change in structure? This investigation will begin with a brief discussion of loads and will analyze two recently constructed works as case studies. The structural systems in these buildings will be examined to see if the conception of loads and the philosophy behind the system is evolving.

\section{Loads and Load Path}

Structure provides support and gives the ability to provide shelter. The Structural Basis for Architecture expands on this observation: "The most obvious and basic function of a structure is its capacity to keep 3 something above ground by bearing loads...thereby establishing inhabitable spaces. ${ }^{2}$ Covering such spaces is accomplished through an arrangement of components including decks (floor and roof), beams, columns, and walls. These elements support their own weight and anything else applied. In determining the particulars of what structure is required, designers look to see what needs are to be met both architecturally and structurally. At a minimum, the building must be strong enough and stable enough to resist physical actions, or loads, placed on the structure. The American Society of Civil Engineers (ASCE), the national professional organization for engineers founded in 1852, provides a definition for loads: "Forces or other actions that result from the weight of all building materials, occupants and their possessions, environmental effects, differential movement, and restrained dimensional changes." 3 Gravity, people, wind, and seismic forces push on the structure, and the members need to carry these loads.

The placement, the size, and number of structural elements are selected, as expected, based partially on these load demands. For an engineer to certify that a building meets the code requirements to protect human life, he or she must determine, evaluate, and state that the building will perform adequately under the expected loads in both strength and stiffness. Loads are a fundamental part of building's structures. Thus, if contemporary practice is transforming building structure, have loads transformed as well? Looking back at early discussions of load may help to answer this question.

While each country has its own standards to determine the level of forces on a structure, the work of ASCE can be used as an example to view some of these changes as it is the primary organization for building engineering in the United States. The American Society of Civil Engineers first examined loads on buildings in 1905 in Paper No. 997, "The Structural Design of Buildings." Prior to this time, design loads had been determined by the city codes. In this paper, ASCE sought to provide a national standard for cities that did not have structural codes and bring consistency to the determination and application of codes across the country. ${ }^{5}$ Development of this document was necessary because of a recent change in the construction of 4 buildings. As the introduction to the paper states, "These specifications are intended to cover only the structural features of buildings of the modern type, in which steel forms a part of the construction...." Building structure had moved from predominantly bearing wall systems to the beginning of steel frame construction. There was great concern in the design of buildings by architects and engineers with the underlying assumption being that some buildings were not being designed safely. ${ }^{7}$ 
Today, ASCE continues to publish this paper as a standard on loads. The use of this standard, now titled ASCE 07 - Minimum Design Loads for Buildings and Other Structures (ACSE 07-10), is engrained in contemporary practice. The 2010 version of this publication is over three hundred pages in length and has been greatly expanded from the original, which consisted of only nineteen half-size pages. In the 1905 version, wind load was covered in three paragraphs and called for a uniform magnitude of force on a building of 30 pounds of load per square foot. In discussions of the original standard, this magnitude was seen by some as too high, while others indicated that there was variation in the behavior of the wind. The current standard addresses wind load in six chapters and 118 pages. What has changed since the 1905 document that requires an explosion of information?

One could argue that various climatic changes have increased the wind demands on structure. The standard's authors do analyze weather data and update the values intermittently based on any changes, but there are other points worth considering. As building structures have been reduced in size and footprint, their response to the wind has become more obvious and severe. In their contemporary practice in 1905, engineers were witnessing the collapse of bare steel structures under wind loading. ${ }^{8}$ Since this time, building structures have continued to become smaller and lighter. Because of these systemic changes to structure, designing for wind has become more of a determining factor than it was one hundred years ago. The force of the wind has not changed significantly, but its impact on structure has. Further requirements were needed to define wind loads in order to accommodate changes in building construction.

Additionally, the knowledge on the behavior of wind has increased significantly with a century of laboratory testing and analysis. The current standard reacts to this data and gives the engineer the ability to consider the behavior of a building under wind with more subtlety. Site conditions such as being in a hurricane zone or being located on top of a hill are now being considered as well as building geometry and building height. This allows for the wind force to vary with the interpretation of the site. The increase in the load requirements can be seen to indicate a change in the way an engineer perceives the conditions in which he or she applies the load. The magnitude of wind loads are at times increased from the prescribed 1905 magnitude and this is due to the change in the understanding and application of the loads over the last century.

Once the magnitude and type of loads are determined, they are conceptually applied to a building and the load path is determined. What is a load path? For buildings, it is the route in which load moves through the structure. For engineers, it is how they believe the load transfers through the structural elements to the ground. The current ASCE 07-10 standard requires that 'All structures shall be provided with a continuous load path...and shall have a complete lateral forcelresisting system with adequate strength to resist the forces...." Developing and designing a complete load path allows the engineer to feel comfortable that structural integrity has been provided. The conceptual load diagram is used by engineers in determining the arrangement of structural members in the construction of a building.

In steel construction today, a load path model can be outlined this way: the weight of the deck and occupants on it the floor distributes load to the beams, the beams load the girders, the girders transmit the forces to the columns, the columns rest on foundations which convey the load to the soil. Connections between the members ensure that the load can travel from one member to another. While this idea of a steel load path is commonplace today; it was not always the case. As steel frame construction was being introduced, there were questions of the importance of the thick masonry walls. ${ }^{10}$ The idea of what was 6 carrying the load was being solidified and not at current levels of refinement. In contemporary architecture, investigations of structure are happening and there is a sense of redefinition. Is the work of the early twenty-first century comparable to the changes at the turn of the twentieth century? Two early buildings have been selected to help evaluate this question the Metropol Parasol in Seville and the Leutschenbach School in Zurich.

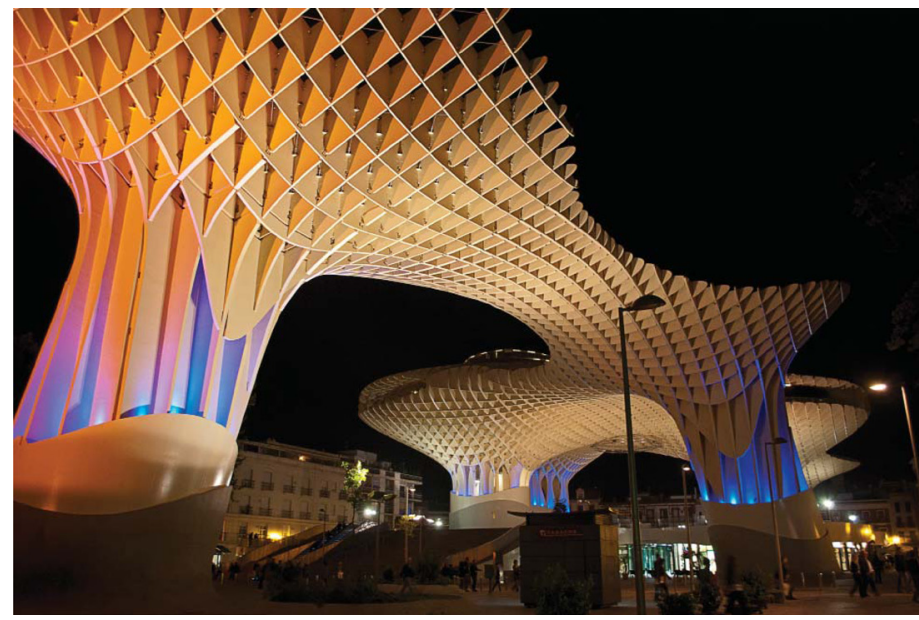

Figure 1: The Metropol Parasol at night. Photo by Anual.

\section{Metropol Parasol (2004-2011)}

The Metropol Parasol was designed by the architectural office of J. Mayer $\mathrm{H}$. Architects with Arup as the structural engineers (figure 1). Located in the Plaza de la Encarnación, in the medieval center of Seville, the design for this project was selected through an international competition held in 2004. The site, originally used as a cloister, was transformed through the centuries into a market square. In the 1970s, there were plans to develop it into parking, but during the excavation for the parking structures, important archaeological discoveries dating from the Roman era were made and the construction was halted. A decision was made at this point, 
in part due to the importance of the finds, to create a use for this plaza that included preserving the site's Roman mosaics and structures.

The civic leadership sought to find an architectural solution which could re-energize this open plaza for the city and take into account the archeological restrictions on ground interventions. The leaders saw the potential of the project as "restoring universal, civil, multifunctional urban space.....along with the restoration of city life in La Encarnación." 11 Not only should the design "offer quality public spaces, but it should include the offer of quality public time." 12

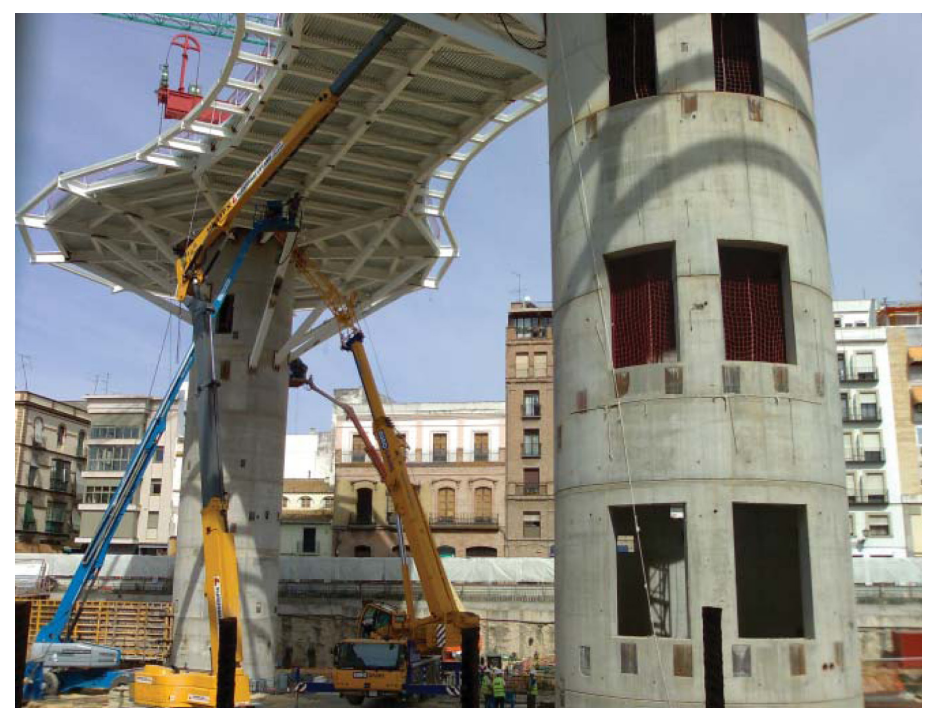

Figure 2. The Metropol Parasol under construction Photo by Torchondo.

Mayer's response was to create a four-level 'building' which incorporates an archaeology museum at its base and culminates in a walkway, which sits above a wooden canopy and allows pedestrians to see both the city and the canopy itself. The eleven thousand square meter canopy has been described as a cloud, as the tops of mushrooms (Les Setas), as a grove of prefabricated wooden trees ${ }^{13}$, and by the architect, as a 7 parasol. However it is interpreted, the canopy is an architectural and engineering achievement. Located at twenty-eight meters above ground level, the canopy is curved in plan and section. While once conceived as an internal structural system to be clad, it is now an open, mostly revealed structure. The final design demands a necessary integration of architecture and structure to create a partial covering for the area. The plaza transforms during the day with the movement of the sun and respite from the heat of the summer is provided by the canopy.

\section{Structure}

The structure of this object is complex. Its variation in form provides interest and demands an innovative structure. There are many interlocking parts which require sophisticated analysis in order for the structure to work at all. If the structure is abstracted, it can be described as a platform supported by columns which are necessitated to bear lightly and specifically on the soil. In this case, the columns are large and hollow. Architecturally, they provide anchors for the cloud-like platform. The columns also function as egress passages from the platform. The material composition of the trunks varies due to the load demand placed on them. Concrete is used for the café and restaurant loads with their heavier loading conditions (figure 2) and wood is used where the walkway that is supported is significantly lighter by comparison.

The members are assembled into a wooden grillage with regular grid spacing ( $1.5 \mathrm{~m} \times 1.5 \mathrm{~m}$ ) to form a $150 \mathrm{~m}$ long and $75 \mathrm{~m}$ wide canopy. The individual pieces are laminated veneer lumber (LVL) panels which range from 68 to 311 millimeters thick and vary in size. ${ }^{14}$ Over three thousand individual pieces which were "cut down to the millimeter by a $\mathrm{CNC} \square$ controlled trimming robot..." 15 were required. Two additional elements allow this structure to work. The first is uniquely developed connection type that bonds a rod to the LVL panel in order to take the vertical along with bending loads. The second is a series of steel diagonal members which stabilize and unify the structure to allow it to behave structurally like a shell. ${ }^{16}$ The 8 essential steel members and connections, however, were designed not to draw away from the overall architectural composition and time was taken to ensure that the visual impact of both was minimized. ${ }^{17}$

\section{Design, Construction, and Integration}

The building which exists today is the result of a tightly synthesized design process that included material performance, structural demands, construction methods, and architectural requirements. After J. Mayer $\mathrm{H}$. Architects won the competition, the project went through an exploration process to determine the construction. Jürgen Mayer $\mathrm{H}$. described working with these kinds of forms, "We might have to invent new ways to build. For the Metropol Parasol, we had no specific idea in advance what material would be [used], and only a vague idea of the structural system." For this project, the demands of the structural system had the added challenges of irregular form with architectural performance requirements, novel use of material, restrictive temperature demands, and questions of assembly.

Wood was eventually chosen as the structural material because of its strength relative to the weight or density of the material. It is relatively light compared to its capacity to carry load. ${ }^{18}$ The wood then needed to be fabricated and developed into the support system. The interconnection of the members is also a critical design element and steel fasteners were conceived. The weight of the fasteners adds to the load of the structure, so they had to be refined to minimize the amount of material while ensuring that, at the same time, they could carry the required demands. As architectural modifications of the form occurred, the changes had to be coordinated with a structural analysis of the wooden members and weight/capacity investigations of the connections. It was a highly 
integrative process. For each change, architectural or engineering based, a new equilibrium had to be met: the form had to work, the members had to be strong enough, the connections had to be able to carry the load, the weight of the connections had to be determined, and then the whole system evaluated again. As the engineers described, "Convergence of the 9 iteration is reached when all geometric and load bearing criteria have been met. Due to the complexity of the geometry, this convergence [could] take up to several days to compute."19

Another crucial component of this structure was the early consideration given to the making of it. The timber panels had to be manufactured, cut, and assembled at a scale not attempted before. The organizational structure between the design team and the timber contractor had been set up to allow for an 'integrated development' of the project and the 'seamless transfer of electronic data' that facilitated analysis to occur on all ends. ${ }^{20} \mathrm{~A}$ 'virtual object model' was created by the fabricator and then wooden shapes were nested onto sheets of the LVL before being cut. ${ }^{21}$ For the assembly of the pieces, the connection design had to provide for construction tolerances and for the ease of construction the design needed to incorporate many levels of input. In this project, from analysis to construction, digital technology was integral to its success as it provided a means for it to be fabricated. Lessons can be drawn from the integrated design process, the use of digital technology, the challenges in fabrication, and the way the system is loaded.

\section{A New Loading Condition}

This project is a built example of digital form-making. Using contemporary tools, the image has successfully left the two-dimensional screen to become actualized. As an icon, it is successful. As architecture, urban planning, and place-making, it will be judged by the residents of Seville and its tourists, architectural and otherwise. In terms of structure, it functions and the load is being carried. The unusual loading conditions, including the weight of the platform, are solved.

Structurally, the canopy is taking load in an unexpected manner for this type of construction. Formed of many interconnected pieces acting together, the LVL lattice and steel members provide the horizontal support for the canopy itself and a set of walkways that enable people to walk or load the structure. Placing the load of the walkways on the lattice system in this configuration is novel. Other examples of structural exploration with multi-directional members include the Expodach by Thomas Herzog with engineering by IEZ Natterer, the Metz Centre Pompidou by Shigeru Ban with engineering by Arup, and Serpentine Pavilion by Toyo Ito with Arup. Each of these projects uses a continuity of members to form a roof plane. Unlike the Metropol Parasol, these unusual structural members act only as roof structures. For Expodach, Centre Pompidou Metz, and the Serpentine Pavilion, the mesh-like structures are taking dead loads, live loads, and wind loads only for a roof level demand. The structure of the Metropol is designed to carry people or floor loading in specified areas. None of these other projects do this. This is an application of new loading areas for this system type and while it is limited, it still occurs. So, rather than a traditional post and beam system, a network of intertwined structural members, is carrying a floor load. This is significant because it means that, in this project, an imperceptible boundary of structural behavior has been crossed.

A typical value for the live load for a roof structure in the United States is twenty pounds per square foot (psf), meaning that the maximum load that one square foot is expected to have is twenty pounds. The idea behind this loading value is that one or two people may find their way to the roof for some sort of maintenance. For a walkway or floor the magnitude of load goes up steeply. Live load values can range from 40-100 psf which is a significant increase in demand. To support this additional live load, additional structure members will need to be added, which, in turn, will increase the weight that has to be carried. This increase in load can mean a larger structure (which is then heavier itself and cause its own issues), more cost, and perhaps a loss in architectural lightness. Each of these factors may make pursuit of such a loading condition unattractive, impractical, or unbuildable.

At the Metropol Parasol, it can be observed that a successful structural concept and a workable solution were found for the additional load. Engineers, like architects, are charged with ensuring that their contribution does not lead to a loss of life. A system like that used in the Metropol Parasol is new to floor 11 loading and even with the rigors of testing and analysis performed for this project, unknowns may remain. Decisions will take into account the 'newness' of the structural system. Innovations are integral to structural progress, but structural failures are as well. This is evident by the significant focus of engineering education on the failure mechanisms of structures. One way to ensure a minimal risk is to limit the area of loading or demand. Here, the footprint of the walkways which conveys people on and over the wooden parasol is minimal compared to the available area. Only 350 people are allowed to be on the walkway at one time and given the scale of the project this is a small number. ${ }^{22}$ This restriction on the number of people would have considered egress as well as structural issues. It is uncommon that the walkways and this loading condition exist on this type of structure, so it is understandable that it does so with a restricted area of loading.

The Metropol Parasol is a unique project. Structurally, it is a "hybrid structure' with the LVL panels unable to carry the load without the discrete steel members to unify the system's performance. ${ }^{23}$ The strides forward that this project makes are not based on a false idea of structural honesty, but that of structural innovation. In this case, progress can be marked. As the engineers of the project reflected, "Even though the people who constructed the parasols were accustomed to working on a high technological level, the path to realizing this structure took them again and again into new technological territory." ${ }^{\prime 2}$ It is argued here that that 


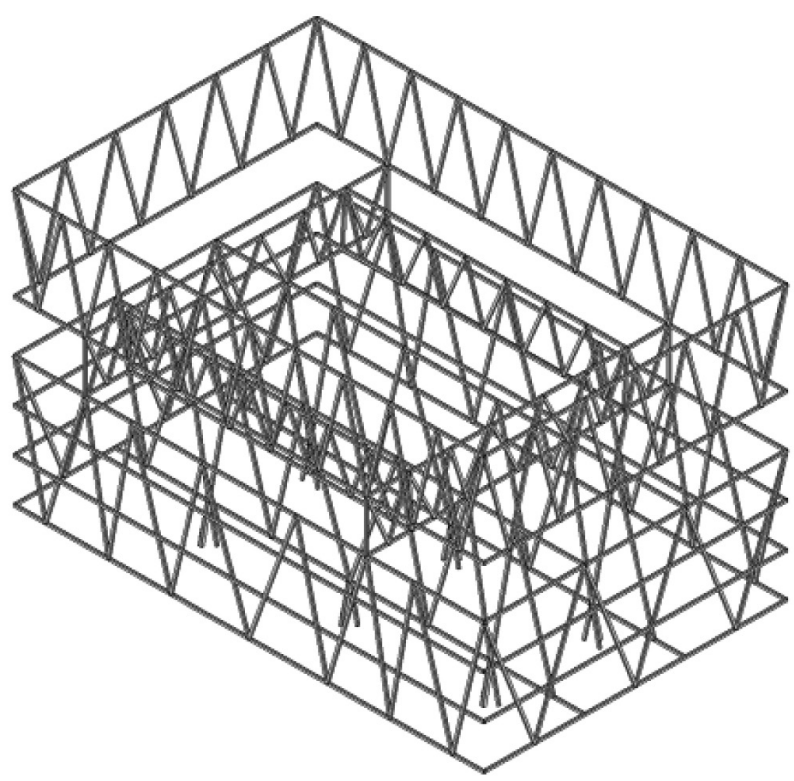

Figure 3. Leutschenbach School Primary Structural Sketch.

the project did cross boundaries, and perhaps it is only the start of things to come. As one reviewer of the project speculates, "In fifty years we will probably be dreaming of things that are unimaginable today, and the Metropol Parasol will likely be recognized as an innocuous expression of a bygone era." ${ }^{25}$ For now, it is an entry step into an exploration of further structural possibilities and loading opportunities.

\section{Leutschenbach School (2004-2009)}

The Leutschenbach School, with Christian Kerez as the architect and Joseph Schwartz as the structural engineer, is a project where structure is partnered with architecture to create an innovative expression of loads. For this building, Kerez stacks units of similar function on top of each other. The programmatic arrangement is resolved and yet refined. There is a vertical distribution of the program that allows much of the site to serve as a park for the school. Areas of the school are grouped in blocks that are logical for the four hundred plus students who use the building. The classrooms are tied together as one unit while the areas of assembly are another. Kerez uses structural members to define these segments of the building and the segmentations are legible from the exterior of the building as well as to the users. For his articulation of these units, an elegant structural solution was needed. A solution had to meet the strength demands and, at the same time, moved literally back and forth across the plan. At first glance, the primary structural frame seems to be an ordinary structural system. On closer observation, however, the loads can be seen to travel in an unusual path.
The school, located in Zurich, Switzerland, appears to float at the ground level. The support at the ground consists of six tripods that are located ten meters from the building's edge. This decision to locate and minimize the ground floor structure gives emphasis to the opening of the building to the park. (Diagrams of the main structure can be seen in figures 3 and 4.) Levels one to three, framed by three story trusses on all sides,

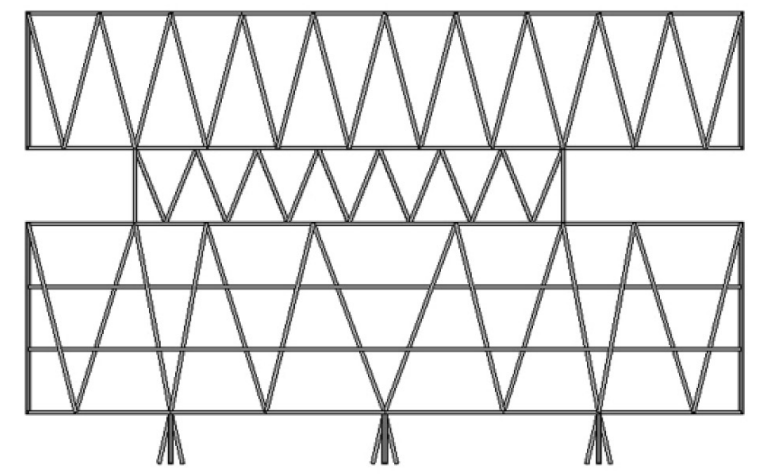

Figure 4. Leutschenbach School Longitudical Structure.

house twenty-two classrooms. A central corridor circulates students into their respective spaces. The four large longitudinal trusses are repeated across the plan at regular intervals, with two on the exterior and two on the interior. Two smaller, perpendicular trusses tie the classroom units together. The diagonal web members of the trusses are exposed and continuous through each of the three levels. At every location within the building, one can perceive which block they inhabit and on which floor they are on due to their location on the exposed diagonal. Careful consideration has been given to how the trusses meet at the corners; with the diagonals coming to a point at the top and, the corners otherwise left clear of structure. In addition to giving vertical organizational cues, the trusses are used to separate the plans into wings. The classrooms are situated between the truss members, and the vertical members do not intrude on the space. Instead, the trusses define the corridor core.

On level four, structure changes as its intended use does. The students mix and assemble on this floor with the library and a lecture hall located here. The large three-story trusses terminate below this level. A onestory truss system is used but turns in plan ninety degrees to provide a wel-defined center. Due to its internal location, the structure appears absent from the elevation of the building at this level. Crucially, for the performance of the structure, two large trusses cross the plan in the opposite direction of the longitudinal trusses above and below it. Two smaller trusses confine the remainder of the internal core.

The final level at the top of the building is a two-story gymnasium which provides a visual identity for the building. Like that of the classroom 
levels, the space is defined by four large external trusses, though the internal trusses are removed here and the space is 'column' free. This allows views from each side of the gymnasium and for the level to light up the building at night. The gymnasium, used by students during the day, is open for community use in the evening. An expanded diagram of the system is provided in figure 5 .

\section{Architecture and Structure}

Christian Kerez's approach to architecture is evident in this building. He states his position as, "I spend considerably more time trying to ask the right questions in terms of architecture and design than trying to solve a given brief." ${ }^{26} \mathrm{At}$ this school, the challenge became arranging the program in a clear and logical system that was organized vertically in order minimize the building's footprint. The essence of the project, however, is the experience of the students and teachers throughout the space, rather than the precise location of the library. A synthesis of the architecture and the structural system can be easily observed. This, too, is important to Kerez and can be seen through such comments as, "In the idea of space all the aspects of architecture blend together in an inseparable unity. Material, color, structure have meaning only 14 because they describe the contours of architectural space. ${ }^{27}$ Kerez succeeds in this goal at Leutschenbach. The steel members support and define the stacked program, yet assemble individual units together on the exterior structure. On the elevations of the building, attention is drawn to the blocks by having major structural elements terminate virtually in mid-air as is the case with both the classroom and gymnasium spaces. One cannot but help to notice the blocks when intuitively they are expected to reached the ground, but do not. Also, using trusses with similar language for the individual pieces, allows for the building to read as a whole. "The result is not a gymnasium on top of an undivided school building, but a structure that consists of repeating references on multiple levels." ${ }^{28}$ The structure segments, unifies, and abruptly changes to serve the architecture. At the same time, the arrangement creates a structural puzzle to be solved. The architectural use of structure, which works so well here, can only happen due to a clever exploration of the load path.

The Vision of Load

In this project, Kerez and Schwartz used recognizable structural members, materials, and construction methods for the structural system. It is with the conceptual load path that the system becomes something of interest. From the top of the building, relatively small, long-span roof trusses cover the gymnasium. The individual trusses bear on the nodes of the much larger two-story vertical trusses which encase the gymnasium space. Loading the structure at the nodes is simple, efficient, and the expected load pattern for the design. From here on, however, the load path leaves the expected routes. The gymnasium floor slab is joined compositely with the steel members and is supported partially from above and from below. The external trusses carry the outer edges of the slab with the inner spans relying on the trusses below. At level
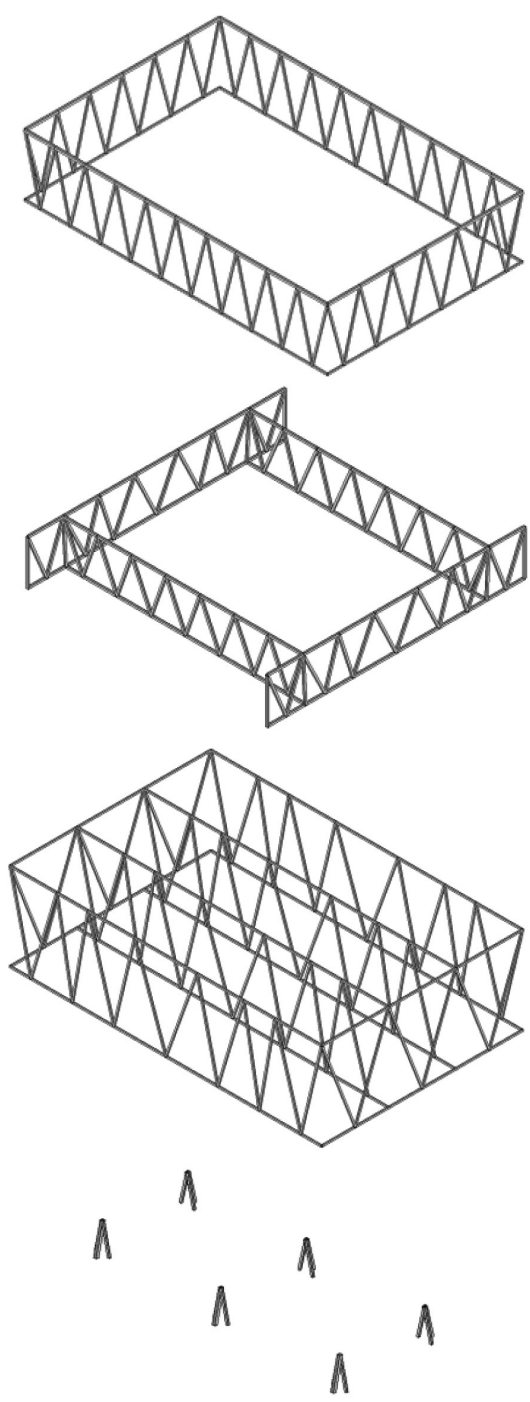

Figure 5. Leutschenbach School Primary Structural Axonometric Sketch.

four, the entire structure changes direction and location (figure 5). The longer gymnasium trusses are supported from below on two internal transfer trusses which span the transverse direction. At the center of the fourth level are two smaller north-south longitudinal trusses which directly load the larger trusses below. Because of the support arrangement, this fourth level exists as a unit between units. The slab 15 above it is partially supported by the upper trusses which in turn load the transfer trusses. The slab below is supported on the giant trusses below.

Levels one to three also have a mixture of supports. The slabs are supported compositely at each level by the four longitudinal trusses. At the base, the two interior trusses are supported on six tripods (figure 6). 
The location of these tripods allows for the interior trusses to cantilever on each end. The exterior trusses, remarkably are supported not from the bottom, but from the top by the transfer trusses at level four (figure 7). This is evident from the construction sequence ${ }^{29}$ and from the location of the truss. The size of the slab demonstrates that there are not significant members cantilevering from the core, and the size of the chord members are shallow enough to disappear in the slab. At the ground level, the building rests on tripods which provide a small, but laterally stable structure.

The arrangement of the load bearing elements is unusual and causes some interesting construction challenges. One 'side effect' of the alignment is deflection of the structural members and its impact on the cladding construction. Deflection, or vertical movement from horizontal, is mathematically related to load. The structure deforms with each application of load. Here, the entire structural system deflected differently at various stages of the construction. This can be seen in the loading of the transfer trusses on the fourth level. These trusses in particular are loaded by the three-story trusses at the lower levels of the building. Next, the transfer system is loaded from above by the gymnasium. Thus, the final and reliable location of the fourth level trusses would not be known until the whole structure was constructed and it was loaded from above and below. Crucially, the deflection of the steel frames has to be reached before the glass walls could be placed. The glass will have specific tolerances and the deflection of the supporting structural members will need to be set to ensure their additional deflection does not damage or break the glass. The physical distribution of load through this extraordinary load path had to occur before the building could be enclosed.

\section{The idea of the structure}

One critic summarizes a too common state of structural systems that try to be different, "The present tendency to create forms that defy statics of the pillar beam scheme is tangible, but most of the constructions do not get beyond mere theatrical effects: removal of a few pillars, compensated for by a cumbersome, irritating structure that then has to be hidden." ${ }^{30}$ In this project, Kerez, in collaboration with engineer Joseph Schwartz, succeeds in finding a solution where the structure is revealed, clear, and relatively light. It is not burdened by heavy transfer points or members, but rather embraces load and gives it whole floors to help find its way to the ground. In addition, the load path is allowed to jog through the building. It flows not downward in straight continuous lines, but down, up, over, and down again. There is a freedom of thought in the development of the load path. In this building, Kerez and Schwartz have found some relief from the verticality of Newton's force, if only temporary, in a creative and innovative structural system arrangement. The result is that the design of the project is enhanced by this exploration and the structure becomes architecture.
In a structural analysis of the building commissioned by an AEC trade magazine, an engineer took issue with the structural arrangement, "... even the trusses themselves are insufficient shape for these sort of loads. This is a structure whose primary function is to define space and volume; a composition using trusses." ${ }^{11}$ This study reveals a few clues about the structure. It is an extraordinary structure, hence the need for a translation of the structure for their readers. Also, the reviewing engineer found the load path choices of the design engineer inefficient and out of the ordinary. The system can be noted as one that not every engineer would consider or find reason enough to pursue. Though the criticlengineer found fault in the structure, he understood its place in building design. Ultimately, the project is heightened by varying of the load paths, and the building is better for it. The system in the end displays a playful exploration indicative of the current moment in architectural and engineering design. The conceptual load path created by Schwartz varies from a traditional, simple, and linear path.

\section{Conclusion}

In each of the case studies, the Metropol Parasol and the Leutschenbach School, technically difficult projects were realized. The engineers of the Parasol recognized their work as breaking through into a "new technological territory." ${ }^{\text {" It }}$ is in this new domain that opportunities of innovation are created. Structural innovation comes in the form of tool development, material understanding, new analysis techniques, and the ability to think around the standards of practice. Why, at this moment, are engineers and architects able to pursue such technically engaging and innovative works? In part, the answer comes from the success of digital technology and from the knowledge the engineers have of the continuum of engineering and their part in it.

In the January 1965 edition of Architectural Record an article asked "Will the computer change the practice of architecture?"33 This article was a summary of a conference held at MIT to address the subject. Among the comments, both positive and negative, was one by William LeMessurier, the renowned American structural engineer. He explained how his office had started to use computer software in the previous year "...and its effect on our own practice has been extraordinary. A whole area of engineering activity has been permanently changed."34 It was the beginning of the transformation of engineering. The level of calculations conducted by the computer could surpass that which was being accomplished by hand. Nowadays, three-dimensional structural analysis models are common place and were used for both the Metropol Parasol and the Leutschenbach School. The analytical capacity of structural models continues to advance with further developments in software surpassing the matrix analysis techniques that are frequently used. ${ }^{35}$ Additionally, like in 1965 , advanced software is becoming more applicable to use in practice. Arup, for example, was able to use a threedimensional, finite element analysis model for the Parasol project. ${ }^{36}$ In addition, the engineers used an 'automated calculation routine'37 to allow 
an iterative design of the members and the connections. The combination of advanced member analysis and scripting allows for a more sensitive design of the structure. Systems such as this, once ill-understood, can now be 18 found to work. The design team can move forward with confidence so that projects such as these can be built. As the Metropol Parasol engineers concluded, "Ultimately, the project was a success because the participants respected the structure, had the courage to face the challenges it presented, and were extraordinarily committed to the task." ${ }^{38}$ Also, they had the computational power to do so.

In his book, Building: 3000 Years of Design Engineering and Construction, William Addis argues that engineering began when planning was required to construct a building. ${ }^{39}$ The size of a large stone element gave it great weight and therefore could only be put in place with careful consideration. If this is the case, engineers have existed for thousands of years. With each new generation of engineer, experience has been passed from one generation to the next. The modern profession accomplishes this through a university education, project experience, and documents, such as building codes. In the 1905 ACSE document, "The Structural Design of Buildings" author and the Society's President, Charles C. Schneider created a work that, when examined, demonstrates this continuity in engineering. The 'Table of Live Loads' 40 in his document is a tool that engineers used to find design live loads for various floor types. The derivation of this table came from determining live loads from multiple cities, an examination of research, and after vigorous discussion among ACSE members. That table still exists in the ASCE Standard 07-10, though titled differently. Some of the values have changed from 1905, but others have not. The tool itself remains consistent and the contemporary engineer is using the experience of past engineers along with the data that they have accumulated.

The engineers of both the Metropol Parasol and the Leutschenbach School are doing much of the same. While the work they are doing is novel, it can occur because the steps forward that they taking are on the same path as those that came before them. Today, using the theories developed in the seventeenth century in which beams are examined or material stress is consider, engineers can apply these formulas to new load arrangements or applications. The exploration of structure here is aligned with the engineering 19 discipline's approach to innovation. Skill, knowledge, and experience are used as springboards to advance the field. New instruments may be derived or new material use may occur as long as it can be examined through the contemporary understanding of engineering. The American Society of Civil Engineers has been careful to allow for alternate solutions in the contemporary standard. "Analysis shall employ rational methods based on accepted principles of engineering mechanics and shall consider all significant sources of deformation and resistance." ${ }^{41}$ If it can be proven to work, then it will be accepted. ${ }^{42}$ Perhaps, ACSE recognizes through this statement that engineers can continue to push the field forward if allowed the opportunity to do so.
Loads, as engineers have always known them, can be applied through the lens of each era and consequently be evaluated for an indication of change.

The examples presented here are by no means the only projects which are pushing the limits of structural understanding. Rather they represent two areas of development. The Metropol Parasol uses digital technology in the analysis, fabrication, and construction of a large scale project. The advanced computational analysis allowed the engineers to ensure that the system would work and was buildable. The structure is able to be loaded in a new way that allows people to experience the lattice structure. The Leutschenbach School is an example of fairly normative construction whose members transfer the load around an unusual path. Innovation came by using the traditional material understanding, a developed analysis, and breaking away from the most direct vertical load path. The success of this project is that the structure is not only challenging, but also comfortable. The discontinuities are possible because of the confidence and imagination of the engineer in the structural parti of this non-traditional system. The author William Addis has also suggested that the history of structures is related directly to the ability of the engineer to predict the future behavior of the structure. ${ }^{43}$ Thus, "One strand of the history of building engineering then, is to trace how engineers have generated that necessary confidence before construction commences." ${ }^{44}$ The confidence in the designs of the two case studies were found by limiting risk, progressing in small steps, using high-level analysis, and applying original thinking to loading and load path.

Each of these projects pushes forward the discussion of what is and what is not possible in structural engineering. Is the industry on the verge of crossing into a new understanding of structure in a large sense? Will engineers change the way building structure is conceived? This paper argues that while architecture has not left the boundaries of post and beam and of simple load paths, structures are now formed through prolific experimentation and are constantly approaching the edge of something new. As architects continue to push for new form and a higher level of structural synthesis within a project, structure will inevitably change. Is it possible to have a new model of creating building structure - one as revolutionary as that from load bearing wall to frame construction? Change will not come instantaneously, but it will progress until a there is enough evidence to push the industry forward. The Metropol Parasol and Leutschenbach School may be two of these steps. 


\section{Endnotes}

1 From the introduction to Informal by Cecil Balmond, Prestel: London, 2002.

2 Sandacker, Bjørn Normann, Eggen, Arne Petter and Mark Cruvellier. The Structural Basis of Architecture. New York: Routledge, 2011.

3 American Society of Civil Engineers. Minimum Design Loads for Buildings and Other Structures. Reston: American Society of Civil Engineers, 2010.

4 Schneider, C.C. "The Structural Design of Buildings, Paper No. 997." Transactions of the American Society of Civil Engineers 54 (1905): 371. $5 \mathrm{lbid} ., 371-372$.

$6 \mathrm{lbid}$.

7 This can be seen in the discussion among the members on the proposed paper.

8 Schneider, C.C. "The Structural Design of Buildings, Paper No. 997." Transactions of the American Society of Civil Engineers 54 (1905): 379. 9 American Society of Civil Engineers. Minimum Design Loads for Buildings and Other Structures. Reston: American Society of Civil Engineers, 2010.

10 Misa, Thomas J. A Nation of Steel: The Making of Modern America, 1865-1925. Baltimore: Johns Hopkins University Press, 1995.

11 Steingräber, Cristina Inês. and Sebastian Hoffmann, eds. J. Mayer H.: Metropol Parasol: Redesigning Of Plaza De La Encarnación in Sevilla. Berlin: Staatliche Museen Zu Berlin, 2005.

12 lbid.

13 Webb, Michael. "Metropol Parasol, Seville, Spain." Architectural Review 229: 1372 (June 2011): 60.

14 Koppitz, Jan-Peter et al. "Metropol Parasol - Digital Timber Design." Computational Design Modelling 2 (2012): 251.

15 lbid., 256.

16 lbid., 252.

17 Kucharek, Jan-Carlos. "iAy, caramba! Technical Offsite." Construction Manager (June 2011): 34.

$18 \mathrm{lbid}$.

19 Koppitz, Jan-Peter et al. "Metropol Parasol - Digital Timber Design." Computational Design Modelling 2 (2012): 254.

20 lbid., 253.

21 lbid., 256. 21

$22 \mathrm{lbid}$.

23 Lepik, Andres and Andre Santer, eds. Metropol Parasol: J. Mayer H. Ostfildern: Hatje Cantz, 2011.

$24 \mathrm{lbid}$.

25 Baraona Pohl, Ethel. "Waffle Urbanism." Domus 947 (May 2011): 33.

26 Kerez, Christian, Marquez Cecilia, Fernando and Richard C. Levene, eds. "Christian Kerez, 2000-2009: Fundamentos Arquitectonicos = Basics on Architecture." Madrid: El Croquis, 2009.

27 Steinmann, Martin with Christian Kerez. "Model and Reality." Casabella, $73: 781$ (2009): 116 [English Translation].
28 "Kerez, Christian, Marquez Cecilia, Fernando and Richard C. Levene, eds. "Christian Kerez, 2000-2009: Fundamentos Arquitectonicos = Basics on Architecture." Madrid: El Croquis, 2009.

29 Kerez, Christian. http://www.kerez.ch/projects/, accessed 04/04/2012.

30 Cêtre, Jean-Pierre. "Beyond the Pillar-Slab Model." Casabella 73: 781 (2009): 113 [English translation].

31 Woods, Brendan. "Zürich: Christian Kerez recalls the spirit of early modern schools at Leutschenbach." Architecture Today 209 (2010): 1214. Accessed 04/04/2012.

32 Lepik, Andres and Andre Santer, eds. Metropol Parasol: J. Mayer H. Ostfildern: Hatje Cantz, 2011.

33 Barnett, Jonathan. "Will the Computer Change the Practice of Architecture?" Architectural Record, 137 (January 1965).

$34 \mathrm{lbid}, 144$.

35 This modeling method is still heavily and appropriately used today.

36 Lepik, Andres and Andre Santer, eds. Metropol Parasol: J. Mayer H. Ostfildern: Hatje Cantz, 2011.

37 lbid.

$38 \mathrm{lbid}$.

39 Addis, William. Building: 3000 Years of Design Engineering and Construction. London: Phaidon Press, 2007.

40 Schneider, C.C. "The Structural Design of Buildings, Paper No. 997." Transactions of the American Society of Civil Engineers 54 (1905): 491. 41 American Society of Civil Engineers. Minimum Design Loads for Buildings and Other Structures. Reston: American Society of Civil Engineers, 2010.

42 It should be noted that the requirements for proof are more severe with these types of structures.

43 Addis, William. Building: 3000 Years of Design Engineering and Construction. London: Phaidon Press, 2007.

44 lbid. 